\title{
Therapeutically administered ribonucleoside analogue MK-4482/EIDD-2801 blocks SARS-CoV-2 transmission in ferrets
}

\author{
Robert M. Cox ${ }^{1,2}$, Josef D. Wolf ${ }^{1,2}$ and Richard K. Plemper ${ }^{1}{ }^{\bowtie}$
}

The coronavirus disease 2019 (COVID-19) pandemic is having a catastrophic impact on human health'. Widespread community transmission has triggered stringent distancing measures with severe socio-economic consequences. Gaining control of the pandemic will depend on the interruption of transmission chains until vaccine-induced or naturally acquired protective herd immunity arises. However, approved antiviral treatments such as remdesivir and reconvalescent serum cannot be delivered orally ${ }^{2,3}$, making them poorly suitable for transmission control. We previously reported the development of an orally efficacious ribonucleoside analogue inhibitor of influenza viruses, MK-4482/EIDD-2801 (refs. ${ }^{4,5}$ ), that was repurposed for use against severe acute respiratory syndrome coronavirus 2 (SARS-CoV-2) and is currently in phase II/III clinical trials (NCT04405570 and NCT04405739). Here, we explored the efficacy of therapeutically administered MK-4482/ EIDD-2801 to mitigate SARS-CoV-2 infection and block transmission in the ferret model, given that ferrets and related members of the weasel genus transmit the virus efficiently with minimal clinical signs ${ }^{6-9}$, which resembles the spread in the human young-adult population. We demonstrate high SARS-CoV-2 burden in nasal tissues and secretions, which coincided with efficient transmission through direct contact. Therapeutic treatment of infected animals with MK-4482/ EIDD-2801 twice a day significantly reduced the SARS-CoV-2 load in the upper respiratory tract and completely suppressed spread to untreated contact animals. This study identified oral MK-4482/EIDD-2801 as a promising antiviral countermeasure to break SARS-CoV-2 community transmission chains.

MK-4482/EIDD-2801 is the orally available pro-drug of the nucleoside analogue $N^{4}$-hydroxycytidine (NHC), which has shown potent anti-influenza virus activity in mice, guinea pigs, ferrets and human airway epithelium organoids ${ }^{4,10,11}$. Acting through the induction of error catastrophe in virus replication ${ }^{4,12}$, NHC has broad-spectrum anti-RNA virus activity. In addition to ameliorating acute disease, we have demonstrated in a guinea pig transmission model that NHC effectively blocks the spread of influenza virus from infected animals to untreated contact animals ${ }^{11}$.

Several mouse models of severe acute respiratory syndrome coronavirus 2 (SARS-CoV-2) infection have been developed, some of which were also employed to confirm the in vivo efficacy of MK-4482/EIDD-2801 against betacoronaviruses ${ }^{13}$. However, human SARS-CoV-2 cannot productively infect mice without viral adaptation or introduction of human ACE2 into transgenic animals, and none of the mouse models support transmission to uninfected mice ${ }^{14}$. Spill-back of SARS-CoV-2 to farmed minks, subsequent large-scale mink-to-mink transmission and, in some cases, zoonotic transmission back to humans revealed efficient viral spread among members of the weasel genus without previous adaptation $^{6-9}$. Although mink farms reported elevated animal mortality and gastrointestinal and respiratory clinical signs ${ }^{15}$, outbreak follow-up revealed continued intra-colony spread for extended periods of time ${ }^{9}$, suggesting that the acute clinical signs in the majority of infected animals may be mild. These mink field reports corroborated results obtained with experimentally infected ferrets showing that mustelids of the weasel genus transmit SARS-CoV-2 efficiently without strong clinical disease manifestation ${ }^{16,17}$. As this presentation of SARS-CoV-2 infection resembles the experience of frequently asymptomatic or mildly symptomatic SARS-CoV-2 spread in the human young-adult population ${ }^{18}$, ferrets represent a relevant model species to assess therapeutic impact on SARS-CoV-2 transmission.

To first validate host invasion and tissue tropism of SARS-CoV-2 in ferrets, we inoculated animals intranasally with either $1 \times 10^{4}$ or $1 \times 10^{5}$ plaque-forming units (p.f.u.)-low- and high-inoculum group, respectively-of SARS-CoV-2 clinical isolate 2019-nCoV/ USA-WA1/2020 per animal. The shed virus burden was monitored daily over a period of $10 \mathrm{~d}$. The virus load in the upper and lower respiratory tract was determined for two animals from each inoculum group on days four and ten after infection, respectively.

Virus release from the upper respiratory tract peaked three days after infection and was undetectable by day seven in the animals of the high-inoculum group (Fig. 1a and Supplementary Table 1). Infection of animals in the low-inoculum group was less efficient. The shedding profiles correlated closely with the infectious particle load in nasal turbinates; a heavy virus tissue burden in the high-inoculum group was present on day four, which decreased substantially by approximately four orders of magnitude by day ten (Fig. 1 b and Supplementary Table 2).

Infection with a low concentration of inoculum resulted in low virus loads in the turbinates on day 4 and undetectable burden thereafter. However, quantitation of viral RNA copy numbers in the turbinates using RT-qPCR revealed the continued presence of moderate (approximately $10^{4}$ copies $^{-1}$ tissue) to high $\left(\geq 10^{7}\right.$ copies $\mathrm{g}^{-1}$ tissue) virus loads in the groups with low and high inoculums, respectively (Fig. 1c and Supplementary Table 3). Irrespective of the inoculum concentration, no infectious particles were detected in bronchoalveolar lavages or lung tissue samples (Extended Data Fig. 1). Several organ samples (lungs, heart, kidneys and liver) were also RT-qPCR-negative on both days 4 and 10 (Fig. 1d), confirming

'Institute for Biomedical Sciences, Georgia State University, Atlanta, GA, USA. ${ }^{2}$ These authors contributed equally: Robert M. Cox, Josef D. Wolf. 凶e-mail: rplemper@gsu.edu 
inefficient infection of the ferret lower respiratory tract and limited systemic host invasion. Only the small and large intestine samples were PCR-positive on day 4 after infection, and rectal swabs showed continued low-grade shedding of viral genetic material (Fig. 1e and Supplementary Table 4).

The animals in the high-inoculum group experienced a transient drop in body weight that reached a low plateau on days 5-6 after infection but recovered fully by the end of the study (Fig. If and Supplementary Table 5). One animal in the low-inoculum group showed a gradual slight reduction in body weight until the end of the study (day 10). No other clinical signs, such as fever or respiratory discharge, were noted. The complete blood counts (CBCs) taken every second day revealed no significant deterioration from the normal range in the overall white-blood-cell counts as well as lymphocyte, neutrophil and platelet populations of either inoculum group (Fig. 1g and Supplementary Table 6). The relative expression levels of type I and II interferon in the ferret peripheral blood mononuclear cells (PBMCs) sampled at 48-h intervals reached a plateau approximately $3 \mathrm{~d}$ after infection and stayed moderately elevated until the end of the study (Fig. 1h,i and Supplementary Table 7). IL-6 levels were moderately elevated in some animals but these changes did not reach statistical significance (Fig. 1j). However, we noted a prominent expression peak of select interferon-stimulated genes (ISGs) with antiviral effector function (MX1 and ISG15) $4 \mathrm{~d}$ after infection, followed by a return to baseline expression by the end of the study (Fig. 1k,1).

Before in vivo efficacy evaluation, we validated the potency of NHC against the SARS-CoV-2 clinical isolate 2019-nCoV/ USA-WA1/2020 in cell culture (Fig. 2a). Four-parameter variable slope regression modelling of the dose-response data revealed 50 and $90 \%$ effective concentrations $\left(\mathrm{EC}_{50}\right.$ and $\mathrm{EC}_{90}$, respectively) of approximately $3.4 \mu \mathrm{M}$ and $5.4 \mu \mathrm{M}$, respectively, which is within an approximately sixfold range of potency data reported for other human betacoronaviruses ${ }^{19}$. Based on these results, ferrets were infected with $1 \times 10^{5}$ p.f.u. per animal in the subsequent MK-4482/ EIDD-2801 efficacy tests and the levels of infectious virions in nasal lavages were determined twice daily (Fig. 2b). The viral burden in respiratory tissues was assessed $4 \mathrm{~d}$ after infection. In all treatment experiments, MK-4482/EIDD-2801 was administered twice a day (b.i.d.) through oral gavage. Dosing commenced $12 \mathrm{~h}$ after infection at 5 or $15 \mathrm{mg} \mathrm{kg}^{-1}$ body weight, or $36 \mathrm{~h}$ after infection at $15 \mathrm{mg} \mathrm{kg}^{-1}$. The titres of shed virus in the nasal lavages were equivalent in all MK-4482/EIDD-2801 groups and vehicle-treated controls at the time of the first treatment ( $12 \mathrm{~h}$ after infection), indicating uniform inoculation of all animals in the study (Fig. $2 \mathrm{c}$ and Extended Data Fig. 2a). Initiation of therapy at the 12 -h time point resulted in a significant reduction $(P<0.001)$ of the shed virus load within $12 \mathrm{~h}$, independently of the MK-4482/EIDD-2801 dose administered, and infectious particles became undetectable within $24 \mathrm{~h}$ of the start of treatment. When first administered at the peak of virus shedding (36h after infection), MK-4482/EIDD-2801 completely suppressed the release of infectious virions into nasal lavages within a slightly longer period of $36 \mathrm{~h}$, whereas the vehicle control animals continued to shed infectious particles until the study end.

Only the vehicle-treated animals carried detectable virus burden in their nasal turbinates $3.5 \mathrm{~d}$ after infection (Fig. $2 \mathrm{~d}$ and Extended Data Fig. 2b), indicating that MK-4482/EIDD-2801 had silenced all SARS-CoV-2 replication. SARS-CoV-2 RNA was still detectable in the nasal tissues extracted from animals in all groups, albeit significantly reduced $\left(P=0.0089\right.$ and 0.0081 for the 5 and $15 \mathrm{mg} \mathrm{kg}^{-1}$ MK-4482/EIDD-2801 groups, respectively) in the treated animals versus the vehicle controls (Fig. 2e and Extended Data Fig. 2c). The animals in the 12-h therapeutic groups showed a significant reduction $(P \leq 0.044)$ in effector ISG expression compared with the vehicle-treated animals, although no significant differences in relative interferon and IL-6 induction were observed (Extended Data Fig. 3a-f).

These results demonstrate the oral efficacy of therapeutic administration of MK-4482/EIDD-2801 against acute SARS-CoV-2 infection in the ferret model. Consistent with our previous pharmacokinetic and toxicology work-up of MK-4482/EIDD-2801 in ferrets, treatment did not cause any phenotypically overt adverse effects, and the white-blood-cell and platelet counts of the drug-experienced animals remained within the normal range (Extended Data Fig. 4).

SARS-CoV-2 shedding into the upper respiratory tract of ferrets establishes conditions for the productive spread from the infected source to uninfected contact animals ${ }^{16,17}$. To assess transmission efficiency, we co-housed intranasally infected source animals with two uninfected contact animals each for a period of $3 \mathrm{~d}$, starting $30 \mathrm{~h}$ after the inoculation of the source animal (Fig. 3a). Nasal lavages and rectal swabs were obtained daily from all of the animals and blood was sampled at the start of the study and on days four and eight after the original infection. The viral burden and RNA copy numbers in the respiratory tissues were determined at the end of the co-housing phase (source animals) and at study termination (contact animals).

Infectious particles first emerged in the nasal lavages of some contact animals $24 \mathrm{~h}$ after the start of co-housing (Fig. $3 \mathrm{~b}$ and Supplementary Table 8). By the end of the co-housing phase, all contact animals were infected and approached the peak virus-replication phase, demonstrating that transmission of SARS-CoV-2 among ferrets is rapid and highly efficient.

A second cohort of source animals inoculated in parallel with SARS-CoV-2 received oral MK-4482/EIDD-2801 at a dose of $5 \mathrm{mg} \mathrm{kg}^{-1}$ body weight, administered b.i.d. starting $12 \mathrm{~h}$ after

Fig. 1 SARS-CoV-2 infects the upper respiratory tract of ferrets. Ferrets ( $n=4$ biologically independent animals) were intranasally inoculated with either $1 \times 10^{4}$ or $1 \times 10^{5}$ p.f.u. 2019-nCoV/USA-WA1/2020. a, Virus titre in nasal lavages collected daily. LOD, limit of detection. b-f, At 4 and 10 d post infection, two ferrets from each group were killed and the infection was characterized. $\mathbf{b}$, Number of infectious virus particles in the nasal turbinates. c, Viral RNA was present in the nasal turbinates of all of the infected ferrets. d, Number of viral RNA copies, determined using quantitative PCR with reverse transcription ( $R T-q P C R$ ), in select organs extracted from infected ferrets 4 or $10 \mathrm{~d}$ after infection. Two lung lobes (right (R.) and left (L.) cranial) per animal; SI, small intestine; LI, large intestine. e, Detection of 2019-nCoV/USA-WA1/2020 RNA in rectal swabs of ferrets inoculated with $1 \times 10^{5}$ p.f.u. RNA was extracted from the rectal swabs and the absolute copy numbers were determined using RT-qPCR. f, Body weight of ferrets, measured daily and expressed as a percentage of their weight at day $0 . \mathbf{g}$, CBC analysis, performed every second day. No noticeable differences were detected for any of the parameters tested, including total white blood cells (WBCs), lymphocytes, neutrophils and platelets. The shaded green areas represent the range of normal Vetscan HM5 laboratory values. h-I, Select interferon and cytokine responses in PBMCs harvested every two days after infection. Analysis by RT-qPCR relative to day 0 for animals infected with $1 \times 10^{5}$ p.f.u. 2019-nCoV/USA-WA1/2020. h,i, The infected ferrets displayed elevated expression of ifn- $\beta$ (h) and ifn- $\gamma(\mathbf{i})$. j, Only some animals had moderately elevated levels of il-6. $\mathbf{k}, \mathbf{l}$, The interferon-stimulated genes $m \times 1$ ( $\mathbf{k}$; $P=0.0192$ on day 4 ) and isg15 ( $\mathbf{I} ; P=0.009$ and $P<0.0001$ on days 2 and 4 , respectively) showed a sharp peak on day 4 after infection. The number of independent biological repeats ( $n$, individual animals) is shown for each subpanel. Statistical analysis was performed using a two-way analysis of variance (ANOVA) with Dunnett's post-hoc multiple comparison test. Symbols represent independent biological repeats (individual animals), lines connect the group mean \pm s.d. $(\mathbf{a}, \mathbf{e}-\mathbf{I})$ and bar graphs show the mean (b-d). 
infection. Productive infection of these animals was validated by the titres of SARS-CoV-2 in the nasal lavages $1 \mathrm{~d}$ after infection (Fig. 3b), which very closely matched those seen in the initial efficacy tests (Fig. 2c). Although we also co-housed the treated source animals with two untreated contacts each for nearly $3 \mathrm{~d}$, no infectious SARS-CoV-2 particles were detected in any of the series of nasal lavages obtained from these contacts throughout the study or in any of the nasal turbinates sampled from the contact animal at end of the study (Fig. 3c and Supplementary Table 9).

The nasal turbinates extracted from the contacts of the vehicle-treated source animals contained high copy numbers of viral RNA, underscoring successful host invasion after transmission
(Fig. 3d and Supplementary Table 10). Consistent with our earlier observations, the turbinates of the treated source animals harboured moderate-to-high ( $\geq 10^{5}$ copies $^{-1}$ tissue) levels of viral RNA, although infectious particles could not be detected. In contrast, all respiratory tissues of the contacts co-housed with the source animals treated with MK-4482/EIDD-2801 remained SARS-CoV-2-genome free, indicating an absence of any low-grade virus replication that could have hypothetically progressed in these animals below the detection level of infectious particles (Fig. $3 \mathrm{e}, \mathrm{f}$ and Supplementary Tables 11,12). Furthermore, SARS-CoV-2 RNA was present at low copy numbers in the intestinal tissue samples and rectal swabs of the vehicle source animals as well as their contacts but undetectable

a

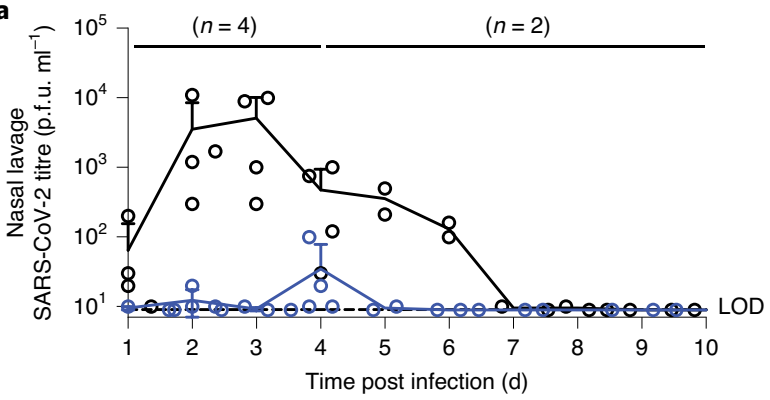

- - SARS-CoV-2, $1 \times 10^{4}$ p.f.u. $(n=4)$

- - SARS-CoV-2, $1 \times 10^{5}$ p.f.u. $(n=4)$

d

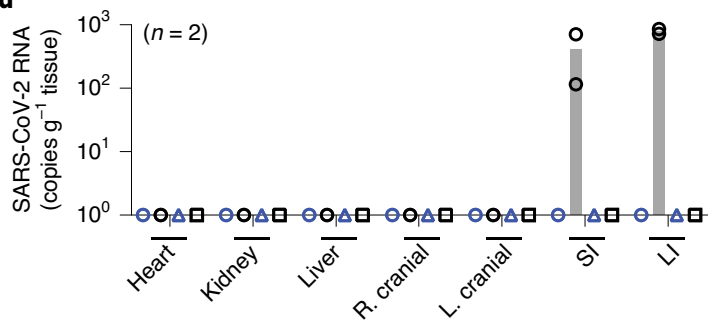

O Day 4, SARS-CoV-2, $1 \times 10^{4}$ p.f.u. $\triangle$ Day 10 , SARS-CoV-2, $1 \times 10^{4}$ p.f.u. - Day 4 , SARS-CoV-2, $1 \times 10^{5}$ p.f.u. $\square$ Day 10, SARS-CoV-2, $1 \times 10^{5}$ p.f.u.

g
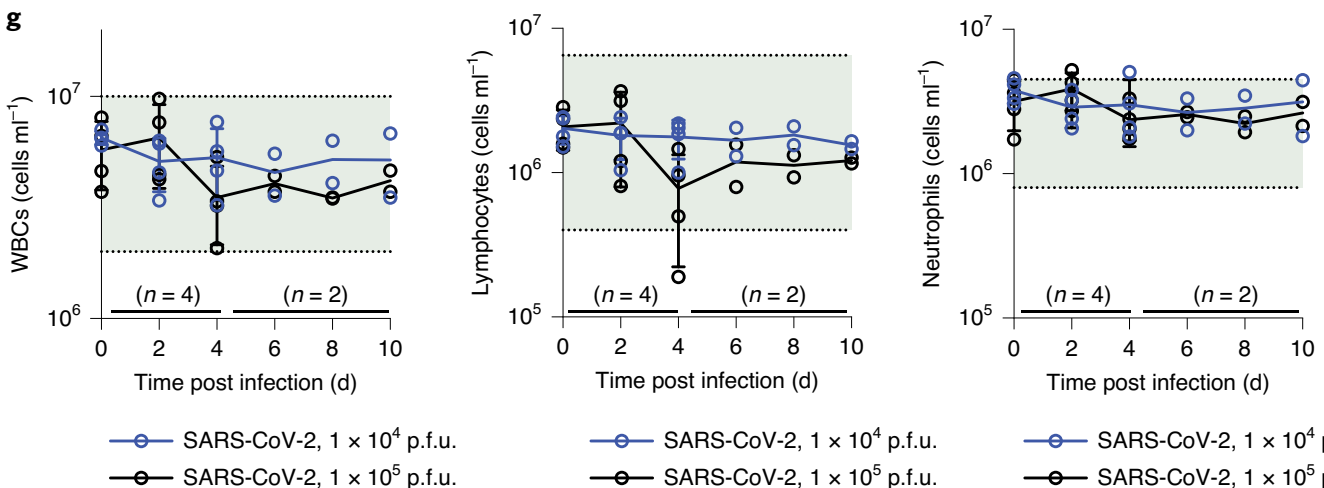

- SARS-CoV-2, $1 \times 10^{4}$ p.f.u

- - SARS-CoV-2, $1 \times 10^{4}$ p.f.u

- - SARS-CoV-2, $1 \times 10^{5}$ p.f.u.
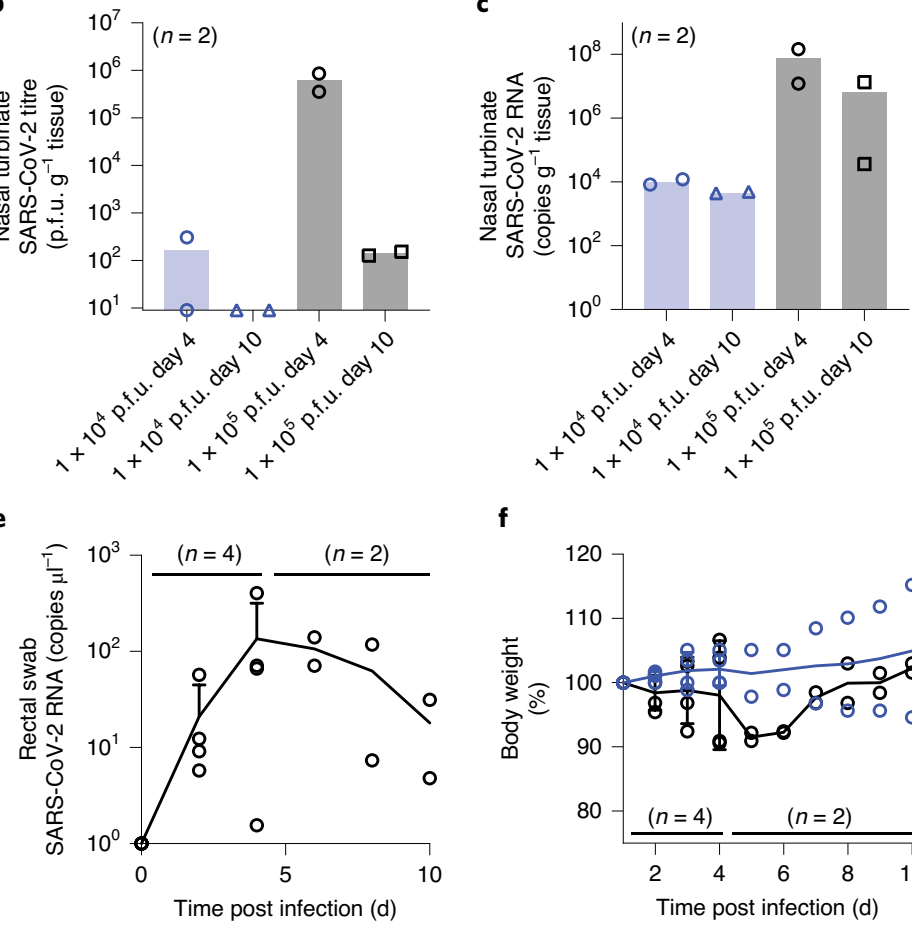

f
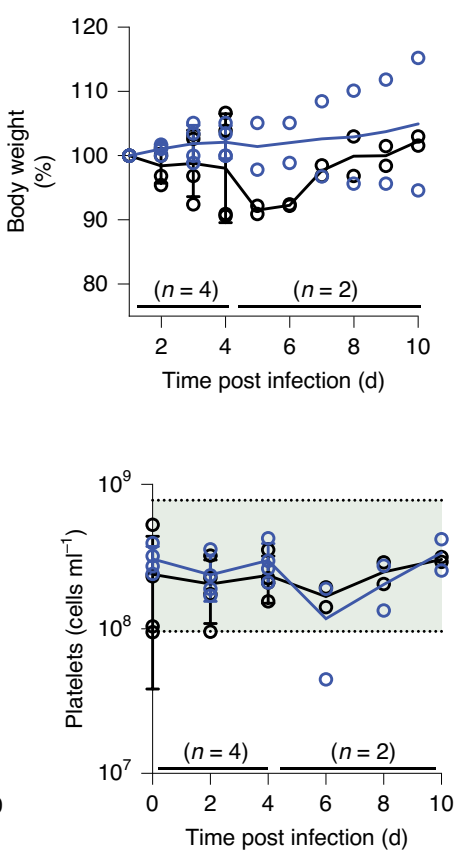

- - SARS-CoV-2, $1 \times 10^{4}$ p.f.u - SARS-CoV-2, $1 \times 10^{5}$ p.f.u.

h

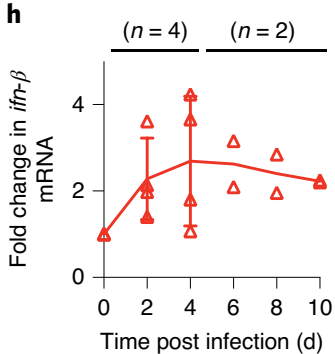

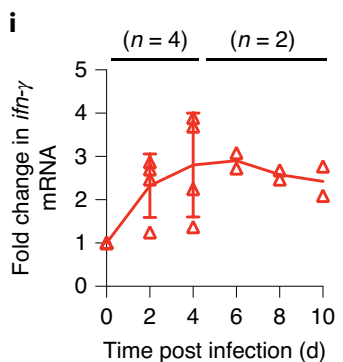

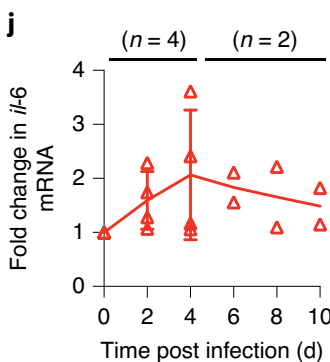

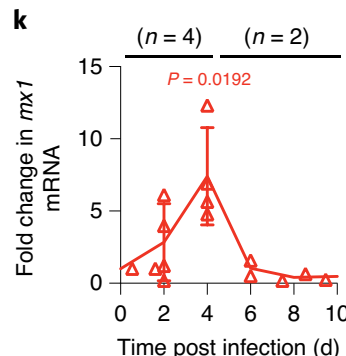

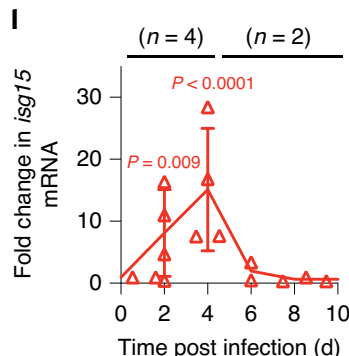



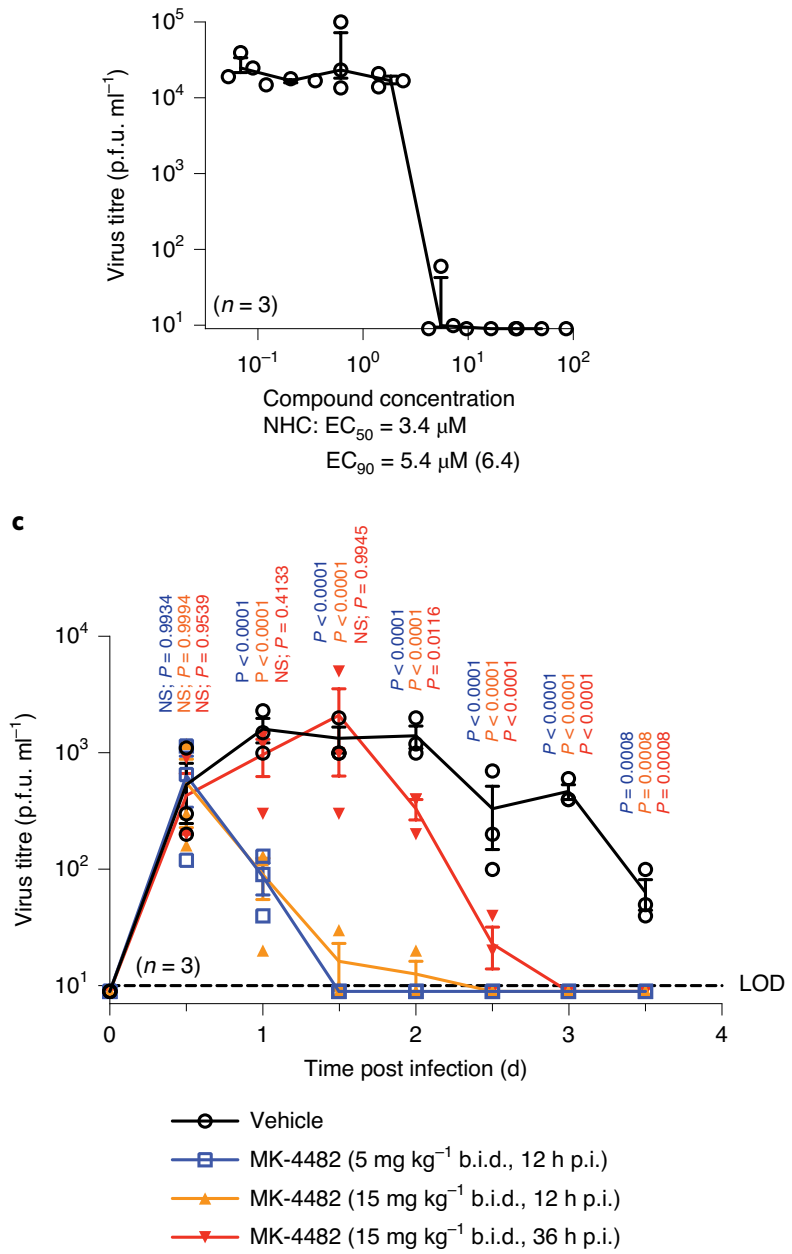
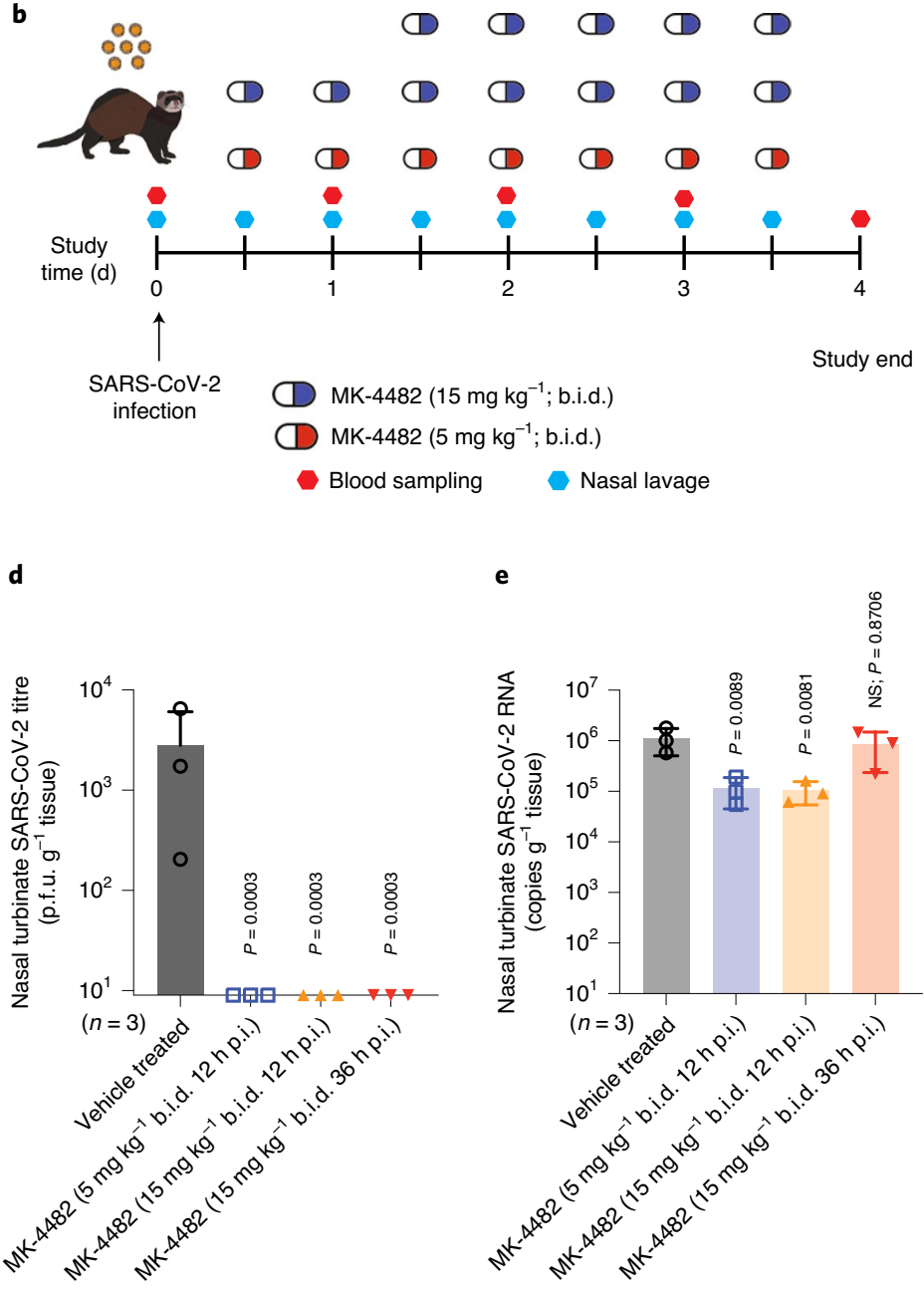

Fig. 2 | Therapeutic MK-4482/EIDD-2801 is orally efficacious against SARS-CoV-2 in ferrets. a, Dose-response inhibition test of NHC against SARS-CoV-2 in Vero E6 cells (multiplicity of infection of 0.1 p.f.u. per cell; $n=3$ biologically independent experiments). The effective concentrations (EC 50 and $\mathrm{EC}_{90}$, shown with the upper $95 \%$ confidence interval limit in parenthesis) were derived from four-parameter variable slope regression modelling. b, Schematic of the therapeutic efficacy study. Ferrets ( $n=3$ biologically independent animals) were infected intranasally with $1 \times 10^{5}$ p.f.u. $2019-n C o V /$ USA-WA1/2020 and either gavaged with vehicle or treated b.i.d. with MK-4482/EIDD-2801 commencing 12 (5 mg kg-1 and 15 mg kg-1) or 36 h (15 mg kg ${ }^{-1}$ ) after infection. Nasal lavages were collected twice a day and blood was collected every other day. Yellow circles represent SARS-CoV-2 and SARS-CoV2-infected source animals. c, Viral titres of the nasal lavages of the infected ferrets from $\mathbf{b}$. Treatment with MK-4482/EIDD-2801 significantly reduced the virus titres within $12 \mathrm{~h}$ of dosing onset in all treatment groups. Statistical analysis was performed using a two-way ANOVA with Dunnett's multiple comparison post-hoc test. d,e, Infectious particle (d) and viral RNA copy (e) numbers in the nasal turbinates of infected ferrets extracted 4 d after infection. Statistical analysis was performed using a one-way ANOVA with Dunnett's multiple comparison post-hoc test. c-e, $P$ values are shown; NS, not significant; p.i., post infection. The number of independent biological repeats is shown for each panel. Symbols represent independent biological repeats (individual animals), lines connect the group mean \pm s.d. (a,c) and bar graphs show the mean \pm s.d. (d,e).

in the MK-4482/EIDD-2801-treated source group and co-housed contact animals.

Phylogenetic analysis of outbreaks in mink farms revealed prolonged intra-colony circulation and zoonotic mink-to-human transmission ${ }^{9}$, leading us to select ferrets-members of the weasel genus closely related to minks-as a SARS-CoV-2 transmission model. We noted that the experimental infection of ferrets was strongly dependent on the amount of viral inoculum used. Productive host invasion was only observed after intranasal delivery of $1 \times 10^{5}$ p.f.u. SARS-CoV-2. The shed SARS-CoV-2 load in ferret nasal lavages, a core virological marker of a transmission model, showed good cross-study consistency. Our experiments returned peak shed virus titres of $1 \times 10^{3}-1 \times 10^{4}$ p.f.u. $\mathrm{ml}^{-1}$, closely resembling the ferret lavage titres found in two previous studies, which reported up to $1 \times 10^{4}$ p.f.u. $\mathrm{ml}^{-1}$ (ref. ${ }^{20}$ ) and
$1 \times 10^{3}$ median tissue culture infectious dose $\mathrm{ml}^{-1}$ (ref. ${ }^{21}$ ) in nasal lavages, respectively.

Natural infection through direct contact was highly efficient, possibly reflecting the prolonged exposure of contact to source animals in a confined space. However, nearly all contacts started to shed virus within less than $24 \mathrm{~h}$ after the beginning of co-housing. This timeline indicates that transmission must have occurred shortly after the introduction of contact to the source animals, despite the fact that the shed viral titres of the source animals were only $1 \times 10^{3}$ p.f.u. $\mathrm{ml}^{-1}$ nasal lavage in this disease period. Transmission of SARS-CoV-2 between ferrets through the air has recently been demonstrated ${ }^{22}$. Our results underscore that natural infection with SARS-CoV-2 through large droplets, aerosols and/or fomites is highly productive.

MK-4482/EIDD-2801 is currently being tested in advanced multi-centre clinical trials, which were launched after the successful 
completion of phase I safety trials (that is, NCT04392219). Although the dosages applied in these studies and human pharmacokinetic data have not yet been disclosed, Merck \& Co. have revealed ${ }^{23}$ that NHC reached levels in human blood that were safe and exceeded antiviral concentrations against SARS-CoV-2 in primary human airway epithelia cultures ( $\mathrm{NHC} \mathrm{EC}_{90}$ of approximately $0.5-1 \mu \mathrm{M}$; ref. ${ }^{13}$ ). Our pharmacokinetic profiles for MK-4482/EIDD-2801 revealed that NHC plasma concentrations $\geq 0.5 \mu \mathrm{M}$ at trough $(12 \mathrm{~h}$ after dosing based on a b.i.d. regimen) are reached after oral doses of approximately 130 and $10 \mathrm{mg} \mathrm{kg}^{-1}$ were administered to cynomolgus
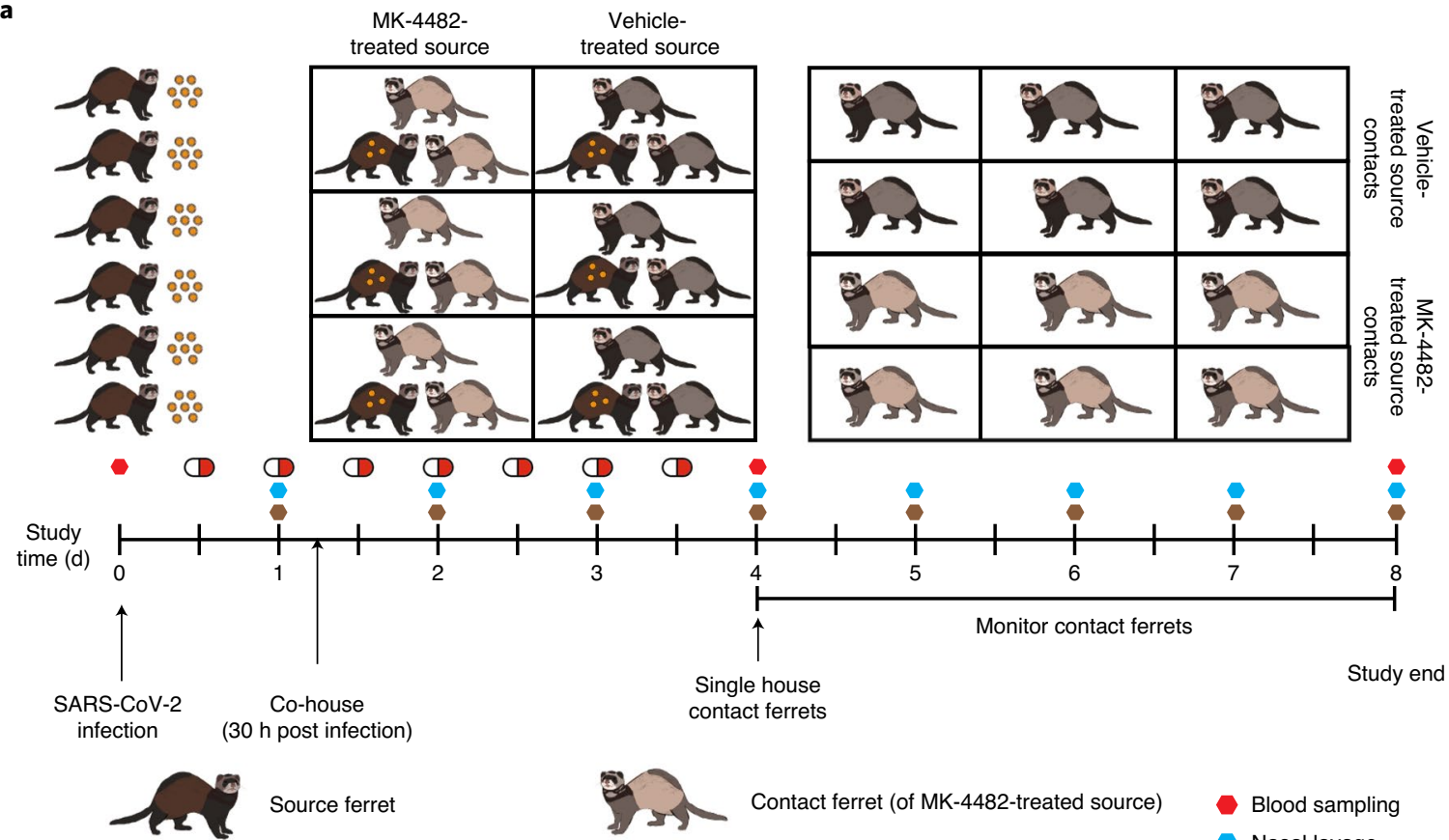

(1) MK-4482 (5 mg kg${ }^{-1}$; b.i.d.)
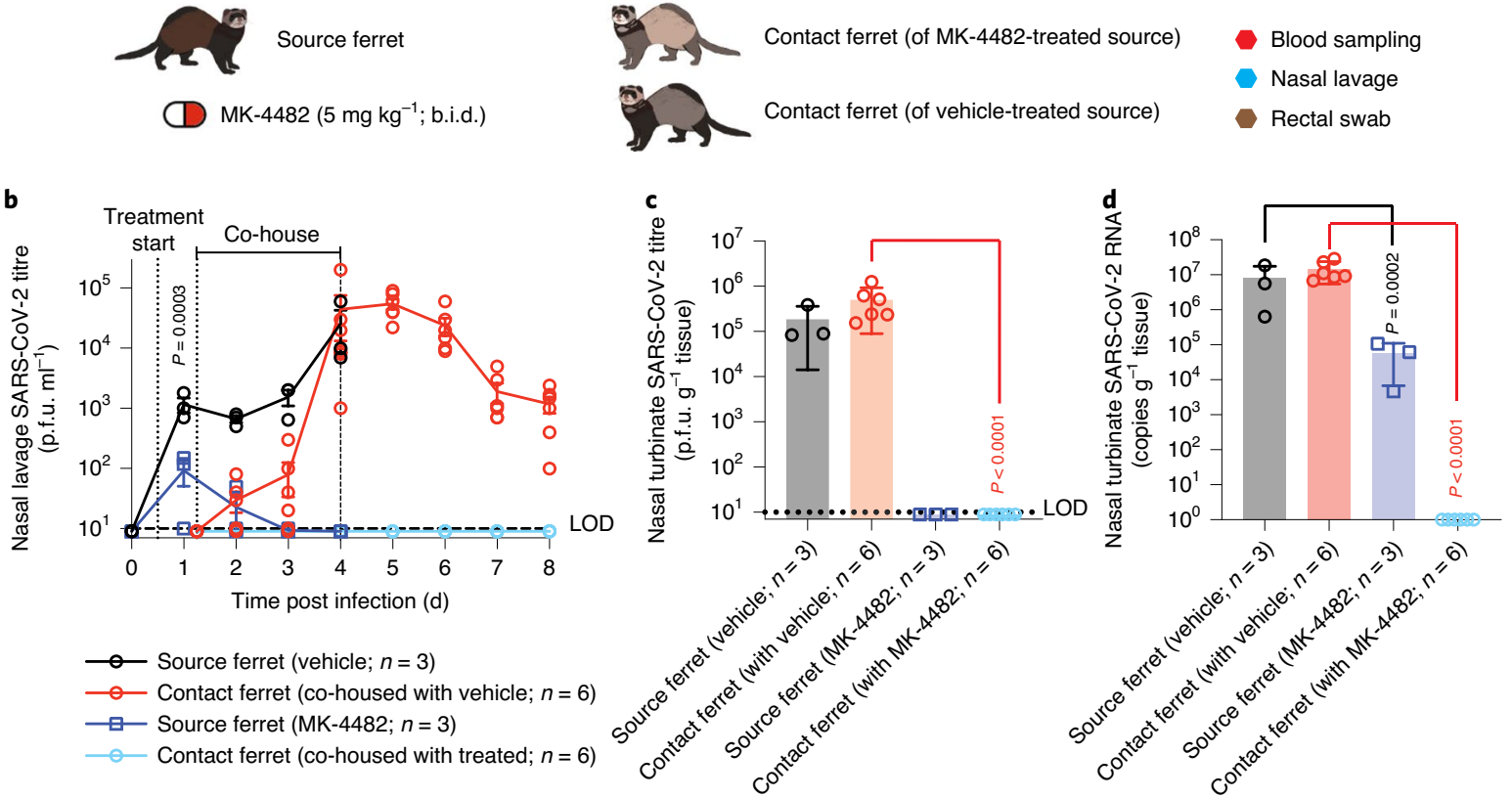

e

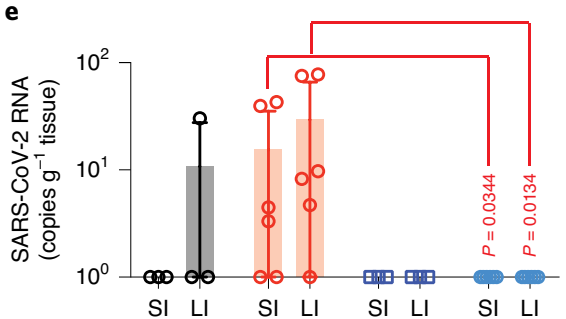

$\multimap$ Source ferret (vehicle; $n=3$ )

- Contact ferret (co-housed with vehicle; $n=6$ )

$\square$ - Source ferret (MK-4482; $n=3$ )

$-\odot$ Contact ferret (co-housed with treated; $n=6$ )

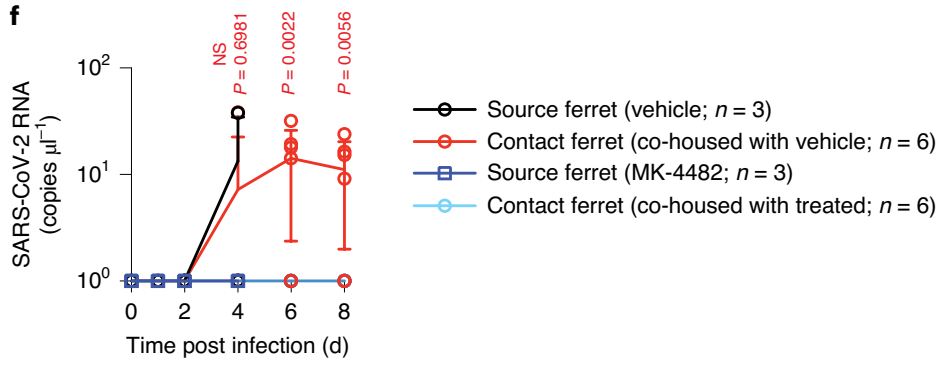


Fig. 3 | Therapeutic oral treatment with MK-4482/EIDD-2801 prevents contact transmission. a, Schematic of the contact transmission study. Two groups of source ferrets ( $n=3$ biologically independent animals each) were infected with $1 \times 10^{5}$ p.f.u. 2019-nCoV/USA-WA1/2020 and received MK-4482/ EIDD-2801 treatment ( $5 \mathrm{mg} \mathrm{kg}^{-1}$ b.i.d.) or vehicle starting $12 \mathrm{~h}$ after infection. At $30 \mathrm{~h}$ after infection, each source ferret was co-housed with two uninfected untreated contact ferrets. The source animals were euthanized after $3 \mathrm{~d}$, and the contact ferrets were isolated and monitored for $4 \mathrm{~d}$. Nasal lavages and rectal swabs were collected once a day and blood was sampled at 0, 4 and $8 \mathrm{~d}$ post infection. b. Source ferrets treated with MK-4482/EIDD-2801 had significantly lower virus titres than the vehicle animals $12 \mathrm{~h}$ after treatment commencement $(P=0.0003)$. The contacts of the vehicle-treated sources began to shed 2019-nCoV/USA-WA1/2020 within $20 \mathrm{~h}$ of co-housing. No virus could be detected in the untreated contacts of the source ferrets treated with MK-4482/EIDD-2801. Statistical analysis was performed using a two-way ANOVA with Sidak's multiple comparison post-hoc test; $P$ values are shown. $\mathbf{c}, \mathbf{d}$, Infectious particle (c) and viral RNA copy (d) numbers in the nasal turbinates of the source and contact ferrets from $\mathbf{b}$ extracted 4 and $8 \mathrm{~d}$ after the start of the study, respectively. Statistical analysis was performed using a one-way ANOVA with Sidak's multiple comparison post-hoc test (c) $P<0.0001$ for intergroup comparison of contact animals; $\mathbf{d}, P=0.0002$ and $P<0.0001$ for intergroup comparisons of the source and contract animals, respectively). e,f, Viral RNA copy number in the small (SI) and large (LI) intestine (e), and rectal swabs (f). The samples from the source ferrets treated with MK-4482/EIDD-2801 and their contacts were PCR-negative for viral RNA. Statistical analysis was performed using a one-way (e) or two-way (f) ANOVA with Sidak's multiple comparison post-hoc test. The samples being compared in the post-hoc tests (c-f) have been colour-coded black or red for the vehicle-treated source and contact ferrets, respectively. The number of independent biological repeats is shown for each panel. $P$ values are shown. Symbols represent independent biological repeats (individual animals), lines connect the group mean \pm s.d. (b,f) and bar graphs show the mean \pm s.d. (c-e).

macaques and ferrets, respectively ${ }^{4}$. These calculations drove our decision to dose ferrets with the $5 \mathrm{mg} \mathrm{kg}^{-1}$ dose used in this study, which represents a conservative estimate of a safe human-dose equivalent based on all of the available information. Underscoring the high broad-spectrum antiviral potential of the drug, $5 \mathrm{mg} \mathrm{kg}^{-1}$ is also close to the lowest efficacious dose of MK-4482/EIDD-2801 against seasonal and pandemic influenza viruses in ferrets ${ }^{4,10}$.

Closely resembling our previous experience with influenza therapy ${ }^{4,10}$, MK-4482/EIDD-2801 was well tolerated and orally efficacious against SARS-CoV-2, reducing the upper respiratory virus load to below the detection level within $24 \mathrm{~h}$ of the first drug administration when therapy was initiated after the onset of virus shedding and by nearly two orders of magnitude when first administered at the peak of virus replication. Similarly, viral genetic material was undetectable in the gastrointestinal samples of the treated animals, which is consistent with previous observations of a sustained presence of the biologically active triphosphate form of NHC in all soft tissue, except liver, in different species ${ }^{4,12,24}$.

Importantly, treatment suppressed all transmission to the untreated direct contacts despite a prolonged direct proximity of the source and contact animals as well as detectable virus shedding from the source animals at the beginning of the co-housing phase. This complete block may indicate a bottom threshold of the shed SARS-CoV-2 load for successful spread. In addition, the genome integrity of some EIDD-2801-experienced virions shed from the treated animals may have been only partially compromised. Rather than being chain-terminating when incorporated by the viral polymerase, NHC undergoes spontaneous tautomeric interconversions, leading to base pairing either as cytosine or uracil ${ }^{25}$. The resulting randomly positioned transition mutations induce viral error catastrophe ${ }^{26}$, causing a collapse of the virus population. This mechanism of antiviral activity of NHC was demonstrated for alphaviruses ${ }^{12}$, pneumoviruses $^{11}$ and orthomyxoviruses ${ }^{4}$, and confirmed to equally apply to betacoronaviruses ${ }^{19}$ and specifically SARS-CoVs ${ }^{13}$. In our study, a limited presence of the analogue in the viral genomes generated shortly after the start of treatment may have had a greater impact on natural invasion of an immune-competent host in vivo than on virus replication in type I interferon-deficient cultured cells such as the Vero E6 used for titration ${ }^{27}$. This view is consistent with the frequent observation (such as in ref. ${ }^{28}$ ) that many mutant viruses can be propagated in cell culture but are attenuated in vivo and incapable of productive host invasion.

Consistent with the conserved antiviral mechanism of action of NHC across diverse viral targets, several previous attempts to induce robust resistance to the compound in alphaviruses ${ }^{12}$, orthomyxoviruses ${ }^{4}$ and betacoronaviruses ${ }^{19}$ were unsuccessful, indicating a high genetic barrier against viral escape. For betacoronaviruses specifically, a very moderate twofold increase in the $\mathrm{EC}_{90}$ concentration was reported after 30 passages in the presence of inhibitor ${ }^{19}$. Given that these mutations delayed viral replication and thus posed a fitness penalty, it is unlikely that clinical use of MK-4482/EIDD2801 will result in the emergence of pre-existing resistance in circulating virus populations or trigger the appearance of viral variants with enhanced pathogenicity.

Our previous studies with influenza viruses in ferrets ${ }^{4}$ and guinea pigs $^{11}$ furthermore demonstrate that the antiviral efficacy and transmission block by MK-4482/EIDD-2801 are not host-species restricted. A virological study of hospitalized patients with coronavirus disease 2019 (COVID-19) revealed that the average load of SARS-CoV-2 RNA copies detected in human sputum during the peak phase of infection is $7.0 \times 10^{6} \mathrm{copies} \mathrm{ml}^{-1}$ (maximum of $2.35 \times 10^{9}$ copies $\left.\mathrm{ml}^{-1}\right)^{29}$. Attempts at virus isolation from human patients were generally unsuccessful when the samples contained $<1 \times 10^{6} \mathrm{RNA}$ copies $\mathrm{ml}^{-1}$. In ferrets, we found peak shedding titres of $1 \times 10^{3}-1 \times 10^{4}$ p.f.u. $\mathrm{ml}^{-1}$ in the nasal lavages and an earlier study reported that SARS-CoV-2 concentrations of up to $1 \times 10^{4}$ p.f.u. $\mathrm{ml}^{-1}$ ferret nasal lavage correlates to up to $1 \times 10^{8}$ viral RNA copies $\mathrm{ml}^{-1}$ $\left(\right.$ ref. ${ }^{20}$ ). These comparisons suggest that the peak viral RNA copy load in ferret nasal lavages recapitulates that seen in human sputum. At present, the tissue distribution and antiviral efficacy of MK-4482/EIDD-2801 in humans are still unknown. If ferret-based inhibition data of SARS-CoV-2 transmission are predictive of the effect in humans, however, patients with COVID-19 could become non-infectious within $24-36 \mathrm{~h}$ after the onset of oral treatment. Treatment with MK-4482/EIDD-2801, in particular when initiated early after infection, thus has the potential to provide threefold benefits: it may mitigate the risk of progression to severe disease and accelerate recovery, ease the emotional and socio-economic toll associated with mandatory prolonged isolation and aid in rapidly silencing local outbreaks.

\section{Methods}

Study design. Ferrets (Mustela putorius furo) were used as an in vivo model to examine the efficacy of therapeutically administered oral MK-4482/EIDD-2801 against SARS-CoV-2 infection and virus transmission to uninfected contact animals. Viruses were administered to source animals through intranasal inoculation and the virus loads in nasal lavages and rectal swabs were monitored periodically as well as in respiratory tissues and a subset of organs 4 or $10 \mathrm{~d}$ after exposure. The virus titres were determined based on plaque assays and viral RNA copy numbers; blood samples were subjected to CBC analysis and RT-qPCR quantitation of the expression levels of select cytokine and innate antiviral effectors.

Cells and viruses. Vero E6 cells were obtained from the American Type Culture Collection (ATCC CRLK-1586) and cultured in DMEM medium supplemented with $7.5 \%$ heat-inactivated fetal bovine serum (FBS) at $37^{\circ} \mathrm{C}$ with $5 \% \mathrm{CO}_{2}$. SARS-CoV-2 (2019-nCoV/USA-WA1/2020) was propagated using Vero E6 cells 
supplemented with $2 \%$ FBS. The virus stocks were stored at $-80^{\circ} \mathrm{C}$ and titres were determined by plaque assay. Vero E6 cells were authenticated by morphology and susceptibility to virus infection, and routinely checked for bacterial and mycoplasma contamination at intervals of 6 months.

Virus yield reduction assay. Vero E6 cells were seeded in 12-well plates $\left(3 \times 10^{5}\right.$ cells per well) $24 \mathrm{~h}$ before infection. The cells were infected using a multiplicity of infection of 0.1 p.f.u. per cell. SARS-CoV-2 was allowed to adsorb for $1 \mathrm{~h}$ at $37^{\circ} \mathrm{C}$. Subsequently, the virus inoculum was removed and the cells were overlaid with medium containing threefold serial dilutions of NHC $(50-0.68 \mu \mathrm{M})$ in DMEM supplemented with $2 \%$ FBS. The infected cells were incubated with compound for $48 \mathrm{~h}$ at $37^{\circ} \mathrm{C}$, followed by virus titration by plaque assay. The $\mathrm{EC}_{50}$ and $\mathrm{EC}_{90}$ concentrations were calculated using four-parameter variable slope regression modelling.

Plaque assay. Samples were serially diluted (tenfold dilutions starting at a 1:10 initial dilution) in DMEM medium supplemented with $2 \%$ FBS containing Antibiotic-Antimycotic (Gibco). The serial dilutions were added to Vero E6 cells seeded in 12 -well plates at $3 \times 10^{5}$ cells per well $24 \mathrm{~h}$ previously. The virus was allowed to adsorb for $1 \mathrm{~h}$ at $37^{\circ} \mathrm{C}$. Subsequently, the inoculum was removed and the cells were overlaid with 1.2\% Avicel (FMC BioPolymer) in DMEM and incubated for $3 \mathrm{~d}$ at $37^{\circ} \mathrm{C}$ with $5 \% \mathrm{CO}_{2}$. The Avicel was removed and the cells were washed once with PBS, fixed with $10 \%$ neutral buffered formalin and plaques were visualized using $1 \%$ crystal violet.

Establishing the infectious dose. Female ferrets (6-10 months of age) were purchased from Triple F Farms. The ferrets were rested for 1 week following arrival, and then randomly assigned to groups and housed individually in ventilated negative-pressure cages in an ABSL-3 facility. To establish a suitable inoculum for the efficacy and transmission studies, the ferrets $(n=4)$ were inoculated intranasally with $1 \times 10^{4}$ and $1 \times 10^{5}$ p.f.u. $2019-n C o V / U S A-W A 1 / 2020$ in $1 \mathrm{ml}(0.5 \mathrm{ml}$ per nare). The ferrets were anaesthetized with dexmedetomidine/ ketamine before inoculation. Nasal lavages were performed on non-anaesthetized animals once a day using $1 \mathrm{ml}$ PBS containing twofold concentrated Antibiotic-Antimycotic (Gibco). The nasal lavage fluids were stored at $-80^{\circ} \mathrm{C}$ until virus titration through plaque assays on Vero E6 cells. For blood sampling, the ferrets were anaesthetized with dexmedetomidine and approximately $0.5 \mathrm{ml}$ blood was drawn from the anterior vena cava. A Vetscan HM5 (Abaxis) was used to perform CBCs in accordance with the manufacturer's protocol. Rectal swabs were performed every $2 \mathrm{~d}$. Groups of two ferrets were killed 4 and $10 \mathrm{~d}$ post infection and their organs were harvested to determine the virus titres and presence of viral RNA in different tissues.

Animals. The group sizes were three ferrets per condition for all animal experiments. A power calculation $(P<0.05 ; 80 \%$ power $)$ predicted that this sample size was sufficient to detect a difference of $1.19 \log _{10}$ p.f.u. $\mathrm{ml}^{-1}$ in virus titre in ferret nasal lavages. As no statistically informative reference datasets for the SARS-CoV-2 ferret model were available at the start of the study, we based this prospective calculation on our experience with a canine distemper virus ferret infection model that has shown a cumulative s.d. of 0.32 in our laboratory. In the transmission experiments, the ferrets were co-housed at a ratio of one source to two contact animals, three co-housing sets per condition. Incoming animals were randomly assigned to the different study groups; no blinding of investigators was performed.

In vivo efficacy of MK-4482/EIDD-2801 in ferrets. The groups of ferrets were inoculated with $1 \times 10^{5}$ p.f.u. $2019-\mathrm{nCoV} / \mathrm{USA}-\mathrm{WA} 1 / 2020$ in $1 \mathrm{ml}(0.5 \mathrm{ml}$ per nare). At $12 \mathrm{~h}$ after infection, three groups of ferrets were treated b.i.d. with vehicle (1\% methylcellulose) or MK-4482/EIDD-2801 at a dosage of 5 or $15 \mathrm{mg} \mathrm{kg}^{-1}$, respectively. At $36 \mathrm{~h}$ after infection, a fourth group of ferrets began receiving b.i.d. treatment with MK-4482/EIDD-2801 at a dose of $15 \mathrm{mg} \mathrm{kg}^{-1}$. The compound was administered via oral gavage in $1 \%$ methylcellulose. After the start of treatment, b.i.d. dosing was continued until $4 \mathrm{~d}$ after infection. Nasal lavages were performed on all of the ferrets every $12 \mathrm{~h}$. Blood samples were obtained every $2 \mathrm{~d}$ after infection and stored in $\mathrm{K}_{2}$-EDTA tubes (Sarstedt CB 300). CBC analysis was performed on each blood sample in accordance with the manufacturer's protocols. After the $\mathrm{CBC}$ analysis, the red blood cells were lysed with ACK buffer $\left(150 \mathrm{mM} \mathrm{NH}_{4} \mathrm{Cl}, 10 \mathrm{mM} \mathrm{KHCO}_{3}\right.$ and $0.01 \mathrm{mM}$ EDTA $\mathrm{pH}$ 7.4) and the PBMCs were harvested and stored at $-80^{\circ} \mathrm{C}$ in RNAlater until further RT-qPCR analysis was performed. All of the ferrets were euthanized $4 \mathrm{~d}$ after infection and their organs were harvested to determine the virus titres and presence of viral RNA in different tissues.

Contact transmission of SARS-CoV-2 in ferrets. A group of six source ferrets, which were housed individually, were inoculated intranasally with $1 \times 10^{5}$ p.f.u. 2019-nCoV/USA-WA1/2020. Twelve hours after infection, the source ferrets were split into two groups ( $n=3$ each) receiving vehicle or MK-4482/EIDD-2801 treatment at a dose of $5 \mathrm{mg} \mathrm{kg}{ }^{-1}$ b.i.d. by oral gavage. At $30 \mathrm{~h}$ post infection, each source ferret was co-housed with two uninfected and untreated contact ferrets. The ferrets were co-housed until $96 \mathrm{~h}$ after infection, when the source ferrets were euthanized and the contact animals were housed individually. The contact animals were monitored for $4 \mathrm{~d}$ after separation from the source ferrets and then killed. Nasal lavages and rectal swabs were performed on all of the ferrets every $24 \mathrm{~h}$. Blood samples were collected at 0,4 and $8 \mathrm{~d}$ after the source ferret infection. For all ferrets, organs were harvested to determine the virus titres and the presence of viral RNA in different tissues.

Titration of SARS-CoV-2 in tissue extracts. For virus titration, the organs were weighed and homogenized in PBS. The homogenates were centrifuged at 2,000g for $5 \mathrm{~min}$ at $4^{\circ} \mathrm{C}$. The clarified supernatants were harvested and used in subsequent plaque assays. For detection of viral RNA, the harvested organs were stored in RNAlater at $-80^{\circ} \mathrm{C}$. The tissues were ground and the total RNA was extracted using an RNeasy mini kit (Qiagen). RNA was extracted from the rectal swabs using a ZR viral RNA kit (Zymo Research) in accordance with the manufacturer's protocols.

SARS-CoV-2 RNA copy numbers. Detection of SARS-CoV-2 RNA was performed using the nCoV_IP2 primer-probe set (National Reference Center for Respiratory Viruses, Institut Pasteur) targeting the SARS-CoV-2 RdRp gene. An Applied Biosystems 7500 real-time PCR system using the StepOnePlus real-time PCR system was used to perform the RT-qPCR reactions. TaqMan fast virus 1-step master mix (Thermo Fisher Scientific) was used in combination with the nCoV_IP2 primer-probe set to detect viral RNA. To quantitate the RNA copy numbers, a standard curve was created using a PCR fragment (nucleotides 12669-14146 of the SARS-CoV-2 genome) generated from viral complementary DNA using the nCoV_IP2 forward primer and the nCoV_IP4 reverse primer. The RNA values were normalized to the weights of the tissues used.

Systemic interferon and cytokine profiling. The relative expression of interferon, ISGs and cytokines was determined by real-time PCR analysis. RNA was extracted from PBMCs that were harvested at various time points after infection. Complementary DNA was reverse transcribed with SuperScript III (Invitrogen) using oligo-dT primers and analysed by real-time PCR using Fast SYBR Green master mix (Applied Biosystems). The signals were normalized to glyceraldehyde3-phosphate dehydrogenase messenger RNA, analysed using the comparative threshold cycle $\left(\Delta \Delta C_{t}\right)$ method and expressed relative to day 0 of infection for each respective animal. The sequences of the primers used for the analyses are shown in Supplementary Table 13 .

Statistics and reproducibility. The Microsoft Excel (versions 16.42 and 16.43) and GraphPad Prism (version 8.4.3) software packages were used for most of the data collection and analysis, respectively. Reverse transcription RT-qPCR data were collected and analysed using the StepOnePlus (version 2.1; Applied Biosystems) software package. The final figures were assembled using Adobe Illustrator (version CS6). One- or two-way ANOVAs with Dunnett's, Tukey's or Sidak's multiple comparisons post-hoc tests without further adjustments were used to evaluate statistical significance when more than two groups were compared or datasets contained two independent variables, respectively. The specific statistical test applied to individual studies is specified in the figure legends. The Source Data files summarize the statistical analyses (effect size, degrees of freedom and $P$ values) of the respective datasets. Effect sizes between groups in the ANOVAs were calculated as $\eta^{2}=\left(\mathrm{SS}_{\text {effect }}\right) /\left(\mathrm{SS}_{\text {total }}\right)$ for one-way ANOVA and $\omega^{2}=\left(\mathrm{SS}_{\text {effect }}-\left(\mathrm{df}_{\text {effect }}\right)\left(\mathrm{MS}_{\text {error }}\right)\right) / \mathrm{MS}_{\text {error }}+\mathrm{SS}_{\text {total }}$ for two-way ANOVA; $\mathrm{SS}_{\text {effect }}$, sum of squares for the effect; $\mathrm{SS}_{\text {total }}$, sum of squares for total; $\mathrm{df}_{\text {effect, }}$, degrees of freedom for the effect; $\mathrm{MS}_{\text {error }}$ mean squared error. To determine the antiviral potency and cytotoxicity, the effective concentrations were calculated from dose-response datasets through four-parameter variable slope regression modelling; the values have been expressed with $95 \%$ confidence intervals when possible. A biological repeat refers to measurements taken from distinct samples, and the results obtained for each individual biological repeat are shown in the figures along with the exact size ( $n$, number) of biologically independent samples, animals or independent experiments. The measure of the centre (connecting lines and columns) is the mean throughout. The error bars represent the s.d. throughout. For all experiments, the statistical significance level $\alpha$ was set to $<0.05$; exact $P$ values are shown in individual graphs or Supplementary Tables wherever possible.

Ethics statement. All animal work was performed in compliance with the Guide for the Care and Use of Laboratory Animals of the National Institutes of Health and the Animal Welfare Act Code of Federal Regulations. Experiments with SARS-CoV-2 involving ferrets were approved by the Georgia State Institutional Animal Care and Use Committee under protocol A20031. All experiments using infectious SARS-CoV-2 were approved by the Georgia State Institutional Biosafety Committee under protocol B20016 and performed in BSL-3/ABSL-3 facilities at the Georgia State University.

Reporting Summary. Further information on research design is available in the Nature Research Reporting Summary linked to this article. 


\section{Data availability}

All of the data generated or analysed during this study are included in this published article. Source data are provided with this paper.

\section{Code availability}

This study does not use custom codes. All of the commercial computer codes and algorithms used are specified in the Methods section.

Received: 3 November 2020; Accepted: 18 November 2020; Published online: 3 December 2020

\section{References}

1. Rodriguez Mega, E. COVID has killed more than one million people. How many more will die? Nature https://doi.org/10.1038/d41586-020-02762-y (2020).

2. Martinot, M. et al. Remdesivir failure with SARS-CoV-2 RNA-dependent RNA-polymerase mutation in a B-cell immunodeficient patient with protracted Covid-19. Clin. Infect. Dis. https://doi.org/10.1093/cid/ciaa1474 (2020).

3. Humeniuk, R. et al. Safety, tolerability, and pharmacokinetics of remdesivir, an antiviral for treatment of COVID-19, in healthy subjects. Clin. Transl. Sci. 13, 896-906 (2020).

4. Toots, M. et al. Characterization of orally efficacious influenza drug with high resistance barrier in ferrets and human airway epithelia. Sci. Transl. Med. 11, eaax5866 (2019).

5. Toots, M. \& Plemper, R. K. Next-generation direct-acting influenza therapeutics. Transl. Res. https://doi.org/10.1016/j.trsl.2020.01.005 (2020).

6. Salajegheh Tazerji, S. et al. Transmission of severe acute respiratory syndrome coronavirus 2 (SARS-CoV-2) to animals: an updated review. J. Transl. Med. 18, $358(2020)$

7. Oreshkova, N. et al. SARS-CoV-2 infection in farmed minks, the Netherlands, April and May 2020. Euro Surveill. https://doi.org/10.2807/1560-7917. ES.2020.25.23.2001005 (2020).

8. Enserink, M. Coronavirus rips through Dutch mink farms, triggering culls. Science 368, 1169 (2020).

9. Oude Munnink, B. B. et al. Transmission of SARS-CoV-2 on mink farms between humans and mink and back to humans. Science https://doi.org/ 10.1126/science.abe5901 (2020).

10. Toots, M. et al. Quantitative efficacy paradigms of the influenza clinical drug candidate EIDD-2801 in the ferret model. Transl. Res. 218, 16-28 (2020).

11. Yoon, J. J. et al. Orally efficacious broad-spectrum ribonucleoside analog inhibitor of influenza and respiratory syncytial viruses. Antimicrob. Agents Chemother. 62, e00766-18 (2018).

12. Urakova, N. et al. $\beta$-D- $N^{4}-$ Hydroxycytidine is a potent anti-alphavirus compound that induces a high level of mutations in the viral genome. J. Virol. 92, e01965-17 (2018)

13. Sheahan, T. P. et al. An orally bioavailable broad-spectrum antiviral inhibits SARS-CoV-2 in human airway epithelial cell cultures and multiple coronaviruses in mice. Sci. Transl. Med. 12, eabb5883 (2020).

14. Han, K. et al. Lung expression of human ACE2 sensitizes the mouse to SARS-CoV-2 infection. Am. J. Respir. Cell Mol. Biol. https://doi.org/10.1165/ rcmb.2020-0354OC (2020).

15. Bruschke, C. Nature and Food Quality Ministry of Agriculture (Ministry of Agriculture, 2020)

16. Schlottau, K. et al. SARS-CoV-2 in fruit bats, ferrets, pigs, and chickens: an experimental transmission study. Lancet Microbe 1, e218-e225 (2020).

17. Richard, M. et al. SARS-CoV-2 is transmitted via contact and via the air between ferrets. Nat. Commun. 11, 3496 (2020)

18. Davies, N. G. et al. Age-dependent effects in the transmission and control of COVID-19 epidemics. Nat. Med. 26, 1205-1211 (2020).

19. Agostini, M. L. et al. Small-molecule antiviral $\beta-\mathrm{D}-N^{4}$-hydroxycytidine inhibits a proofreading-intact coronavirus with a high genetic barrier to resistance. J. Virol. 93, e01348-19 (2019).
20. Shi, J. et al. Susceptibility of ferrets, cats, dogs, and other domesticated animals to SARS-coronavirus 2. Science 368, 1016-1020 (2020).

21. Park, S. J. et al. Antiviral efficacies of FDA-approved drugs against SARS-CoV-2 infection in ferrets. mBio 11, e01114-20 (2020).

22. Kutter, J. S. et al. SARS-CoV and SARS-CoV-2 are transmitted through the air between ferrets over more than one meter distance. Preprint at bioRxiv https://doi.org/10.1101/2020.10.19.345363 (2020).

23. Merck \& Co. (Ridgeback Biotherapeutics) and Drug Innovations at Emory (DRIVE) - MK-4482 (formerly EIDD-2801). Genetic Engineering and Biotechnology News https://www.genengnews.com/covid-19-candidates/ ridgeback-biotherapeutics-and-drug-innovations-at-emory-drive/(2020).

24. Painter, G. R. et al. The prophylactic and therapeutic activity of a broadly active ribonucleoside analog in a murine model of intranasal Venezuelan equine encephalitis virus infection. Antivir. Res. 171, 104597 (2019).

25. Les, A., Adamowicz, L. \& Rode, W. Structure and conformation of $N^{4}$-hydroxycytosine and $N^{4}$-hydroxy-5-fluorocytosine. A theoretical ab initio study. Biochim. Biophys. Acta 1173, 39-48 (1993).

26. Crotty, S., Cameron, C. E. \& Andino, R. RNA virus error catastrophe: direct molecular test by using ribavirin. Proc. Natl Acad. Sci. USA 98, 6895-6900 (2001).

27. Desmyter, J., Melnick, J. L. \& Rawls, W. E. Defectiveness of interferon production and of rubella virus interference in a line of African green monkey kidney cells (Vero). J. Virol. 2, 955-961 (1968).

28. Cox, R. M. et al. Orally efficacious broad-spectrum allosteric inhibitor of paramyxovirus polymerase. Nat. Microbiol. https://doi.org/10.1038/ s41564-020-0752-7 (2020).

29. Wolfel, R. et al. Virological assessment of hospitalized patients with COVID-2019. Nature 581, 465-469 (2020).

\section{Acknowledgements}

We thank M. Kumar for providing an aliquot of 2019-nCoV/USA-WA1/2020 stock, members of the GSU High Containment Core and the Department for Animal Research for support, and J. Sourimant and A. L. Hammond for critical reading of the manuscript. This work was supported, in part, by Public Health Service grant nos AI071002 (to R.K.P.) and AI141222 (to R.K.P.) from the NIH/NIAID. The funders had no role in the study design, data collection and interpretation or the decision to submit the work for publication.

\section{Author contributions}

R.M.C. and J.D.W. performed the virus-stock preparations; animal inoculations; sampling and necropsies; contributed to the experiment design, data analysis and presentation; and edited the manuscript. R.M.C. performed all of the RT-qPCR experiments and analyses. J.D.W. performed all of the CBC analyses. R.K.P. conceived, designed and coordinated the study; conceived and designed experiments; contributed to the animal inoculations and necropsies; contributed to data analysis and presentation; and wrote the manuscript.

\section{Competing interests}

The authors declare no competing interests.

\section{Additional information}

Extended data is available for this paper at https://doi.org/10.1038/s41564-020-00835-2.

Supplementary information is available for this paper at https://doi.org/10.1038/ s41564-020-00835-2.

Correspondence and requests for materials should be addressed to R.K.P.

Reprints and permissions information is available at www.nature.com/reprints.

Publisher's note Springer Nature remains neutral with regard to jurisdictional claims in published maps and institutional affiliations.

Peer review statement Nature Microbiology thanks the anonymous reviewers for their contribution to the peer review of this work. Peer reviewer reports are available.

(c) The Author(s), under exclusive licence to Springer Nature Limited 2020 


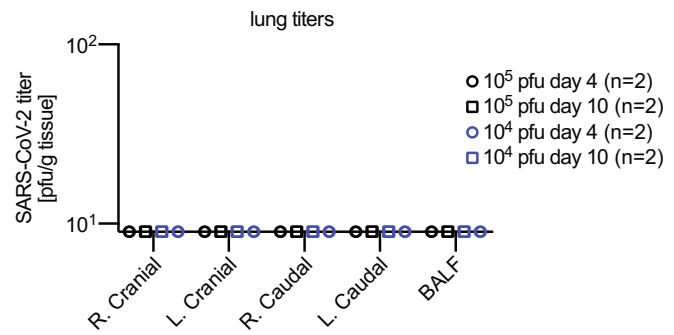

Extended Data Fig. 1 | SARS-CoV-2 does not progress to the ferret lower respiratory tract. Ferrets were inoculated intranasally with $1 \times 10^{4}$ (blue) or $1 \times 10^{5}$ p.f.u. (black) of 2019-nCoV/USA-WA1/2020. a, Analysis of bronchioalveolar lavages (BALF) and four lung lobes (right (R.) and left (L.) cranial and caudal) per ferret. BALF and tissues samples were harvested 4 ( $n=2$ biologically independent animals) and 10 ( $n=2$ biologically independent animals) days after infection. The number of independent biological repeats is shown. Symbols represent independent biological repeats (individual animals). 
Extended Data 2a | Comparison of SARS-CoV-2 titers in nasal lavages of SARS-CoV-2 infected ferrets treated with different doses and dosing regimens

\begin{tabular}{|c|c|c|c|c|c|}
\hline \multirow[b]{2}{*}{ group } & \multirow[b]{2}{*}{ days pl } & \multirow[b]{2}{*}{$\begin{array}{l}\text { mean titer } \\
{[\mathrm{pfu} / \mathrm{ml} l]}\end{array}$} & \multirow[b]{2}{*}{$\begin{array}{c}\mathrm{SD} \\
{[\mathrm{pfu} / \mathrm{ml}]}\end{array}$} & \multicolumn{2}{|c|}{ intergroup comparison: $5 \mathrm{mg} / \mathrm{kg} 12 \mathrm{hpi}$} \\
\hline & & & & $\begin{array}{c}\text { vs } 15 \mathrm{mg} / \mathrm{kg} 12 \mathrm{hpi}^{\mathrm{A}} \\
\text { (P value) }\end{array}$ & $\begin{array}{c}\text { vs } 15 \mathrm{mg} / \mathrm{kg} 36 \mathrm{hpi} \\
\text { (P value) }\end{array}$ \\
\hline \multirow{8}{*}{ vehicle } & 0 & $<$ LoD & n.a. ${ }^{\mathrm{B}}$ & -- & -- \\
\hline & 0.5 & $5.33 \times 10^{2}$ & $4.93 \times 10^{2}$ & -- & -- \\
\hline & 1 & $1.60 \times 10^{3}$ & $6.56 \times 10^{2}$ & -- & -- \\
\hline & 1.5 & $1.33 \times 10^{3}$ & $5.77 \times 10^{2}$ & -- & -- \\
\hline & 2 & $1.40 \times 10^{3}$ & $5.29 \times 10^{2}$ & -- & -- \\
\hline & 2.5 & $3.33 \times 10^{2}$ & $3.21 \times 10^{2}$ & -- & -- \\
\hline & 3 & $4.67 \times 10^{2}$ & $1.15 \times 10^{2}$ & -- & -- \\
\hline & 3.5 & $6.33 \times 10^{1}$ & $3.21 \times 10^{1}$ & -- & -- \\
\hline \multirow{8}{*}{$5 \mathrm{mg} / \mathrm{kg} 12 \mathrm{hpi}$} & 0 & $<$ LoD & n.a. & -- & -- \\
\hline & 0.5 & $6.40 \times 10^{1}$ & $5.15 \times 10^{2}$ & NS; 0.9982 & NS; 0.9816 \\
\hline & 1 & $8.67 \times 10^{1}$ & $4.51 \times 10^{1}$ & NS; 0.997 & NS; 0.068 \\
\hline & 1.5 & $<$ LoD & n.a. & NS; $0.7106^{\star *}$ & NS; $0.0669^{\star *}$ \\
\hline & 2 & $\angle L O D$ & n.a. & NS; $0.7683^{* \star}$ & $0.0107^{\star \star}$ \\
\hline & 2.5 & $<$ LoD & n.a. & -- & NS; $0.4711^{\text {** }}$ \\
\hline & 3 & $<L o D$ & n.a. & -- & -- \\
\hline & 3.5 & $\angle \mathrm{LOD}$ & n.a. & -- & -- \\
\hline \multirow{8}{*}{$15 \mathrm{mg} / \mathrm{kg} 12 \mathrm{hpi}$} & 0 & $<\mathrm{LoD}$ & n.a. & -- & -- \\
\hline & 0.5 & $5.53 \times 10^{2}$ & $5.64 \times 10^{2}$ & -- & NS; 0.9966 \\
\hline & 1 & $9.00 \times 10^{1}$ & $6.08 \times 10^{1}$ & - & NS; 0.1143 \\
\hline & 1.5 & $16.33^{*}$ & n.a. & -- & NS; $0.053^{*}$ \\
\hline & 2 & $12.67^{*}$ & n.a. & -- & $0.0028^{\star}$ \\
\hline & 2.5 & $\angle L O D$ & n.a. & -- & NS; $0.4711^{\star \star}$ \\
\hline & 3 & $<L o D$ & n.a. & -- & -- \\
\hline & 3.5 & $\angle L O D$ & n.a. & -- & -- \\
\hline \multirow{8}{*}{$15 \mathrm{mg} / \mathrm{kg} 36 \mathrm{hpi}$} & 0 & $<\mathrm{LOD}$ & n.a. & -- & -- \\
\hline & 0.5 & $4.33 \times 10^{2}$ & $4.04 \times 10^{2}$ & -- & -- \\
\hline & 1 & $9.67 \times 10^{2}$ & $5.86 \times 10^{2}$ & -- & -- \\
\hline & 1.5 & $2.10 \times 10^{3}$ & $2.54 \times 10^{1}$ & -- & -- \\
\hline & 2 & $3.33 \times 10^{2}$ & $1.15 \times 10^{2}$ & -- & -- \\
\hline & 2.5 & $23^{*}$ & 15.7 & -- & -- \\
\hline & 3 & $<$ LoD & n.a. & -- & -- \\
\hline & 3.5 & $\angle L O D$ & n.a. & -- & -- \\
\hline
\end{tabular}

hpl; hours post infection

Bn.a.; not applicable

\section{Extended Data 2b | SARS-CoV-2 titers in nasal turbinates of ferrets}

\begin{tabular}{|c|c|c|c|c|c|}
\hline \multirow[b]{2}{*}{ group } & \multirow[b]{2}{*}{ days $\mathrm{pl}$} & \multirow[b]{2}{*}{$\begin{array}{l}\text { mean titer } \\
\text { [pfu/ml] }\end{array}$} & \multirow[b]{2}{*}{$\begin{array}{l}\text { std dev. } \\
\text { [pfu/ml] }\end{array}$} & \multicolumn{2}{|c|}{ intergroup comparison: $5 \mathrm{mg} / \mathrm{kg} 12 \mathrm{hpi}$} \\
\hline & & & & $\begin{array}{c}\text { vs } 15 \mathrm{mg} / \mathrm{kg} 12 \mathrm{hpi} \\
\text { (P value) }\end{array}$ & $\begin{array}{c}\text { vs } 15 \mathrm{mg} / \mathrm{kg} 36 \mathrm{hpi} \\
\text { (P value) }\end{array}$ \\
\hline vehicle & 4 & $2.81 \times 10^{3}$ & $3.28 \times 10^{3}$ & -- & -- \\
\hline $5 \mathrm{mg} / \mathrm{kg} 12 \mathrm{hpi}$ & 4 & $<$ L.o.D & n.a. & $\mathrm{NS} ;>0.9999^{* *}$ & $N S ;>0.9999^{* *}$ \\
\hline $15 \mathrm{mg} / \mathrm{kg} 12 \mathrm{hpi}$ & 4 & $<$ L.o.D & n.a. & -- & $\mathrm{NS} ;>0.9999^{* *}$ \\
\hline $15 \mathrm{mg} / \mathrm{kg} 36 \mathrm{hpi}$ & 4 & <L.O.D & n.a. & -- & -- \\
\hline
\end{tabular}

\section{Extended Data 2c | Viral RNA detected in nasal turbinates of ferrets}

\begin{tabular}{|c|c|c|c|c|c|}
\hline \multirow[b]{2}{*}{ group } & \multirow[b]{2}{*}{ days pl } & \multirow[b]{2}{*}{$\begin{array}{c}\text { mean RNA } \\
\text { [copies/g tissue] }\end{array}$} & \multirow[b]{2}{*}{$\begin{array}{c}\text { std dev. } \\
\text { [copies/g tissue] }\end{array}$} & \multicolumn{2}{|c|}{ intergroup comparison: $5 \mathrm{mg} / \mathrm{kg} 12 \mathrm{hpi}$} \\
\hline & & & & $\begin{array}{c}\text { vs } 15 \mathrm{mg} / \mathrm{kg} 12 \mathrm{hpi} \\
\text { (P value) }\end{array}$ & $\begin{array}{c}\text { vs } 15 \mathrm{mg} / \mathrm{kg} 36 \mathrm{hpi} \\
\text { (P value) }\end{array}$ \\
\hline vehicle & 4 & $1.13 \times 10^{6}$ & $6.24 \times 10^{5}$ & -- & -- \\
\hline $5 \mathrm{mg} / \mathrm{kg} 12 \mathrm{hpi}$ & 4 & $1.16 \times 10^{5}$ & $7.10 \times 10^{4}$ & NS; 0.9998 & 0.042 \\
\hline $15 \mathrm{mg} / \mathrm{kg} 12 \mathrm{hpi}$ & 4 & $1.06 \times 10^{5}$ & $5.15 \times 10^{4}$ & -- & 0.0378 \\
\hline $15 \mathrm{mg} / \mathrm{kg} 36 \mathrm{hpi}$ & 4 & $8.64 \times 10^{5}$ & $6.25 \times 10^{5}$ & -- & -. \\
\hline
\end{tabular}

Extended Data Fig. 2 | Experimental means and intergroup comparison of in vivo efficacy study results of MK-4482/EIDD-2801 in SARS-CoV2-infected ferrets. a, Comparison of SARS-CoV-2 titres in nasal lavages of SARS-CoV-2 infected ferrets treated with different doses and dosing regimens. Mean virus titres \pm SD are shown for different study days (days pl). LOD was 10 p.f.u. (a-b). Samples below LOD were plotted as 9 p.f.u. b, SARS-CoV-2 titres in nasal turbinates of ferrets from (a). Mean virus titres \pm SD are shown. L.O.D. was 10 p.f.u. (a-b). c, Viral RNA detected in nasal turbinates of ferrets from (a). Mean RNA copy numbers \pm SD are shown. Statistical significance was determined between different treatment groups. LOD was 1 RNA copy, samples below LOD were plotted as 1 RNA copy. Statistical analysis was performed by two-way (a) or one-way (b-c) ANOVA with Tukey's multiple comparison post-hoc test. P values are shown. $\left(^{\star}\right)$ denotes samples where one or two repeats were below LOD. $\left(^{\star \star}\right)$ denotes all three repeats for at least one dosing group were below LOD. 
a

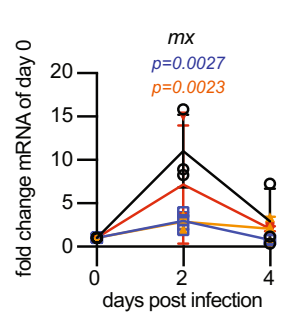

b

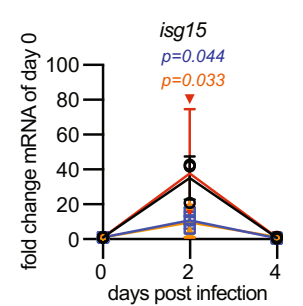

c

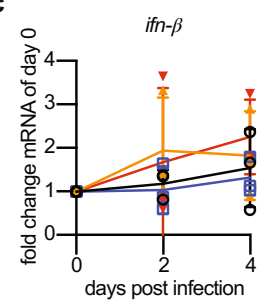

d

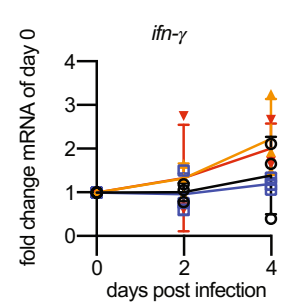

e

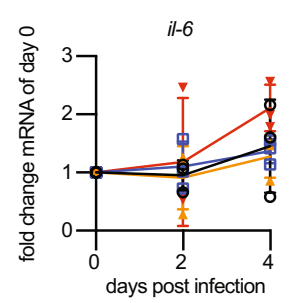

f

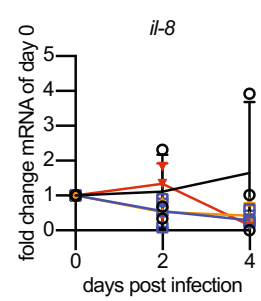

- vehicle treated $(n=3)$

— MK-4482 (15 mg/kg b.i.d. 12 hours pl; $\mathrm{n}=3)$

$\longrightarrow$ MK-4482 (5 mg/kg b.i.d. 12 hours pl; $n=3) \quad \longrightarrow$ MK-4482 (15 mg/kg b.i.d. 36 hours pl; $n=3)$

Extended Data Fig. 3 | Interferon induction and cytokine profiling of SARS-CoV-2 ferrets treated with MK-4482/EIDD-2801. Ferrets ( $n=3$ biologically independent animals) were infected intranasally with $1 \times 10^{5}$ p.f.u. 2019-nCoV/USA-WA1/2020 and either gavaged with vehicle (black (a-f)) or treated b.i.d. with MK-4482/EIDD-2801 commencing 12 ( $5 \mathrm{mg} / \mathrm{kg}$ (blue (a-f)) and $15 \mathrm{mg} / \mathrm{kg}$ (orange (a-f)) or 36-hours (15 mg/kg; red (a-f)) after infection. a-f, Selected interferon and cytokine expression levels in PBMCs relative to day 0. Blood samples of animals treated with MK-4482/EIDD-2801 or vehicle as specified were collected every two days after infection and PBMCs analysed by RT-qPCR. Statistical analysis of changes relative to day 0 by two-way ANOVA with Dunnett's post-hoc multiple comparison test. The number of independent biological repeats ( $n$; individual animals) is shown. In all panels, symbols represent independent biological repeats (individual animals), lines connect group means \pm SD. 
a

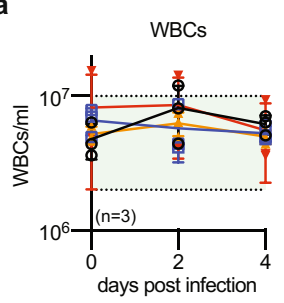

b

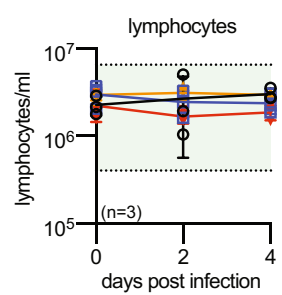

c

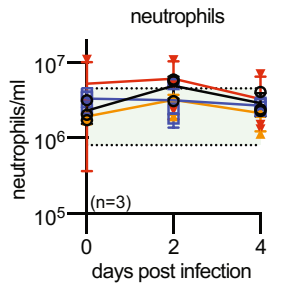

d

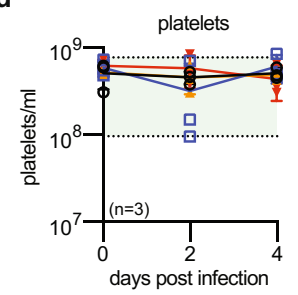

- 1 vehicle treated

$\longrightarrow$ MK-4482 (5 mg/kg b.i.d. 12 hours pl)

$\longrightarrow$ MK-4482 (15 mg/kg b.i.d. 12 hours pl)

$\longrightarrow$ MK-4482 (15 mg/kg b.i.d. 36 hours pl)

Extended Data Fig. 4 | Complete blood count of SARS-CoV-2 ferrets treated with MK-4482/EIDD-2801. Ferrets ( $=3$ biologically independent animals) were infected intranasally with $1 \times 10^{5}$ p.f.u. 2019-nCoV/USA-WA1/2020 and either gavaged with vehicle (black (a-f)) or treated b.i.d. with MK-4482/ EIDD-2801 commencing 12 ( $5 \mathrm{mg} / \mathrm{kg}$ (blue (a-f)) and $15 \mathrm{mg} / \mathrm{kg}$ (orange (a-f)) or 36-hours (15 mg/kg; red (a-f)) after infection. a-d, Blood samples were collected every two days after infection and complete blood counts determined. No abnormal values were observed in all parameters tested, including total WBCs (a), lymphocytes (b), neutrophils (c), and platelets (d). The shaded green areas represent normal Vetscan HM5 lab values. The number of independent biological repeats ( $n$; individual animals) is shown for each subpanel. Symbols represent independent biological repeats (individual animals), lines connect group means \pm SD. 


\section{Reporting Summary}

Nature Research wishes to improve the reproducibility of the work that we publish. This form provides structure for consistency and transparency in reporting. For further information on Nature Research policies, see our Editorial Policies and the Editorial Policy Checklist.

\section{Statistics}

For all statistical analyses, confirm that the following items are present in the figure legend, table legend, main text, or Methods section.

n/a Confirmed

$\square$ ד The exact sample size $(n)$ for each experimental group/condition, given as a discrete number and unit of measurement

$\square$ \ A statement on whether measurements were taken from distinct samples or whether the same sample was measured repeatedly

$\square$ The statistical test(s) used AND whether they are one- or two-sided

$\square$ Only common tests should be described solely by name; describe more complex techniques in the Methods section.

$\bigotimes \square$ A description of all covariates tested

$\square$ \A description of any assumptions or corrections, such as tests of normality and adjustment for multiple comparisons

$\square$ A full description of the statistical parameters including central tendency (e.g. means) or other basic estimates (e.g. regression coefficient)

$\triangle$ AND variation (e.g. standard deviation) or associated estimates of uncertainty (e.g. confidence intervals)

$\square$ For null hypothesis testing, the test statistic (e.g. $F, t, r$ ) with confidence intervals, effect sizes, degrees of freedom and $P$ value noted

Give $P$ values as exact values whenever suitable.

Х $\square$ For Bayesian analysis, information on the choice of priors and Markov chain Monte Carlo settings

Х $\square$ For hierarchical and complex designs, identification of the appropriate level for tests and full reporting of outcomes

\ $\square$ Estimates of effect sizes (e.g. Cohen's $d$, Pearson's $r$ ), indicating how they were calculated

Our web collection on statistics for biologists contains articles on many of the points above.

\section{Software and code}

Policy information about availability of computer code

Data collection Excel (Versions 16.42 and 16.43; Microsoft) was used for most data collection. Reverse transcription qPCR data was collected using an Applied Biosystems StepOnePlus PCR system using the StepOnePlus software (Version 2.1; Applied Biosystems).

Data analysis Statistical analyses were performed in the Prism (GraphPad) software package (version 8.4.3). Figures were composed using Adobe Illustrator (version CS6).

For manuscripts utilizing custom algorithms or software that are central to the research but not yet described in published literature, software must be made available to editors and reviewers. We strongly encourage code deposition in a community repository (e.g. GitHub). See the Nature Research guidelines for submitting code \& software for further information.

\section{Data}

Policy information about availability of data

All manuscripts must include a data availability statement. This statement should provide the following information, where applicable:

- Accession codes, unique identifiers, or web links for publicly available datasets

- A list of figures that have associated raw data

- A description of any restrictions on data availability

All data generated or analyzed during this study are included in this published article (and its supplementary information files). Source data for figures 1-3 and extended data figures 1-3 are provided with the paper in supplementary data file 1. 


\section{Field-specific reporting}

Please select the one below that is the best fit for your research. If you are not sure, read the appropriate sections before making your selection. $\bigotimes$ Life sciences $\quad \square$ Behavioural \& social sciences $\square$ Ecological, evolutionary \& environmental sciences

For a reference copy of the document with all sections, see nature.com/documents/nr-reporting-summary-flat.pdf

\section{Life sciences study design}

All studies must disclose on these points even when the disclosure is negative.

Sample size Appropriate sample sizes were determined using the Resource Equation and Power analysis. Unless otherwise noted, at least three samples were used for each group.

Data exclusions No data was excluded from this manuscript.

Replication All experimental data were reliably produced; the number of independent biological repeats (at least three) and, when applicable, technical repeats is specified for each experiment.

Randomization Animals and samples were randomly sorted into experimental groups.

Blinding The investigators were not blinded to group allocation for data collection and analysis for any experiment performed in this study due to size of the research group with clearance for experimentation under high biocontainment conditions required for work with live SARS-CoV-2. Ferrets are large animals that cannot be handled by a single investigator and resources available did not allow involvement of additional personnel that would have been required for blinding.

\section{Reporting for specific materials, systems and methods}

We require information from authors about some types of materials, experimental systems and methods used in many studies. Here, indicate whether each material, system or method listed is relevant to your study. If you are not sure if a list item applies to your research, read the appropriate section before selecting a response.

Materials \& experimental systems

\begin{tabular}{l|l}
\hline$n / a$ & Involved in the study \\
$\square$ & $\square$ Antibodies \\
\hline & $\bigotimes$ Eukaryotic cell lines \\
$\square$ & $\square$ Palaeontology and archaeology \\
$\square$ & $\square$ Clinical data \\
\hline Dual use research of concern
\end{tabular}

Eukaryotic cell lines

Policy information about cell lines

Cell line source(s)

Authentication

Mycoplasma contamination

Commonly misidentified lines (See ICLAC register)

\begin{tabular}{l|l}
\multicolumn{2}{l}{ Methods } \\
\hline n/a & Involved in the study \\
$\searrow$ & $\square$ ChIP-seq \\
$\searrow$ & $\square$ Flow cytometry \\
$\triangle$ & $\square$ MRI-based neuroimaging
\end{tabular}

Vero-E6 cells, obtained from ATCC.

Cells were authenticated by morphological appearance and susceptibility to virus infection including SARS-CoV-2.

Cell lines were confirmed mycoplasma-negative when obtained from the supplier, followed by preparation and cryopreservation of master and working stocks. Individual working stocks were replaced every three months. All cell lines in use in the laboratory were routinely retested for mycoplasma contamination in 6-months intervals and tested negative.

No commonly misidentified cell lines were used in this study.

\section{Animals and other organisms}

Policy information about studies involving animals; ARRIVE guidelines recommended for reporting animal research 
Field-collected samples

Ethics oversight

Note that full information on the approval of the study protocol must also be provided in the manuscript. Committee under protocol B20016.

Experiments with SARS-CoV-2 involving ferrets were approved by the Georgia State Institutional Animal Care and Use Committee under protocol A20031. All experiments using infectious SARS-CoV-2 were approved by the Georgia State Institutional Biosafety 